07

\title{
Эпитаксиальные напряжения в фотопроводящем слое InGaAs для THz-антенн
}

\author{
(C) Д.И Хусяинов ${ }^{1}$, А.М. Буряков ${ }^{1}$, В.Р. Билык ${ }^{1}$, Е.Д. Мишина ${ }^{1}$, \\ Д.С. Пономарев ${ }^{2}$, Р.А. Хабибуллин ${ }^{2}$, А.Э. Ячменев ${ }^{2}$ \\ ${ }^{1}$ Московский технологический университет „МИРЭА“ \\ ${ }^{2}$ Институт сверхвысокочастотной полупроводниковой электроники РАН, \\ Москва \\ E-mail: Dinar1434429@mail.ru
}

Поступило в Редакцию 7 июля 2017 г.

Методами оптического зондирования при фемтосекундной лазерной накачке (optical pump-probe) и терагерцевой спектроскопии во временно́й области исследовано влияние эпитаксиальных напряжений на динамику неравновесных носителей заряда, а также спектр терагерцевого излучения в пленках $\mathrm{In}_{y} \mathrm{Ga}_{1-y}$ As. Продемонстрировано снижение времени жизни неравновесных носителей заряда и увеличение ширины спектра терагерцевого излучения для пленки $\mathrm{In}_{y} \mathrm{Ga}_{1-y}$ As c бо́льшим механическим напряжением.

DOI: $10.21883 /$ PJTF.2017.22.45260.16958

Источники излучения в терагерцовом (THz) спектральном диапазоне являются востребованными для диагностики разнообразных объектов в медицине, сфере безопасности и науке [1-3]. В настоящее время разработка источников THz-излучения ведется по двум наравлениям: оптимизация формы электродов для генераторов и детекторов THz-излучения [4] и использование новых материалов или модификация свойств уже имеющихся [5]. Тройное соединение $\operatorname{In}_{y} \mathrm{Ga}_{1-y}$ As (где $y-$ мольная доля индия) - хорошо известный материал для фотопроводящих THz-антенн. Такие антенны требуют оптической накачки на длинах волн $0.74-1.5 \mu \mathrm{m}$. Наиболее часто $\mathrm{THz}$-спектроскопии используется соединение $\mathrm{In}_{y} \mathrm{Ga}_{1-y} \mathrm{As}$ с $y=0.53$ благодаря соответствию параметров кристаллической решетки этого соедининия параметрам подложки из фосфида индия (InP). Однако подложки InP достаточно дорогие, хрупкие и обладают более низкой пропускной споосбностью THz-излучения, 
чем подложки из арсенида галлия (GaAs), стоимость которых почти в 2 раза меньше. При этом рассогласование кристаллических решеток $\mathrm{GaAs}$ и $\mathrm{In}_{y} \mathrm{Ga}_{1-y} \mathrm{As}$ можно использовать для создания механических напряжений в эпитаксиальном слое на границе раздела с подложкой, модифицируя свойства материала, применяющегося для генерации или детектирования THz-излучения [6]. Для снижения напряжений в слое $\operatorname{In}_{y} \mathrm{Ga}_{1-y} \mathrm{As}$ используется метаморфный буферный слой (МБ), который чаще всего представляет собой слои широкозонного материала $\operatorname{In}_{x} \mathrm{Al}_{1-x} \mathrm{As}$ с постепенно меняющейся мольной долей индия $x$ от 0.01 до нужного значения мольной доли индия в пленке $\operatorname{In}_{y} \mathrm{Ga}_{1-y}$ As [7]. Количество слоев, толщина и градиент изменения концентрации доли индия в слоях $\operatorname{In}_{x} \mathrm{Al}_{1-x}$ As подбираются специально для наилучшего согласования кристаллических решеток подложки и $\operatorname{In}_{y} \mathrm{Ga}_{1-y} \mathrm{As}$ за счет формирования дефектов в слоях МБ [6].

В настоящей работе было проведено исследование влияния эпитаксиальных напряжений на временнб́е релаксационные константы, ширину THz-спектра и амплитуду THz-излучения пленок $\mathrm{In}_{y} \mathrm{Ga}_{1-y} \mathrm{As}$.

Для исследования динамики носителей заряда, а также генерации THz-излучения было выбрано соединение $\operatorname{In}_{y} \mathrm{Ga}_{1-y} \mathrm{As}$ с $y=0.38$ и $E_{g}=0.918 \mathrm{eV}$. Все образцы изготавливались методом молекулярнолучевой эпитаксии, температура подложки во время роста активных слоев $\operatorname{In}_{y} \mathrm{Ga}_{1-y}$ As составляла $490^{\circ} \mathrm{C}$. Были изготовлены два типа структур: 1) слой $\operatorname{In}_{0.38} \mathrm{Ga}_{0.62} \mathrm{As}$ толщиной $2 \mu \mathrm{m}$, выращенный непосредственно на подложке GaAs (образец $A$ ); 2 ) слой $\operatorname{In}_{0.38} \mathrm{Ga}_{0.62} \mathrm{As}$ на переходном МБ толщиной $\sim 1 \mu$ m также на подложке GaAs (образец $B$ ). МБ состоял из семи слоев $\operatorname{In}_{0,1-0.46} \mathrm{AlAs}$ с постепенным увеличением мольной доли индия и выполнял роль барьера для дефектов и дислокаций, предотвращающего попадание их в фотопроводящий слой. Для минимизации упругих напряжений (образец $B$ ) после МБ перед активным слоем формировалась инверсная ступень. Конструкция образца $B$ показана на рис. 1, более подробно его свойства исследованы в работе [8].

Методика „optical pump-probe“ (далее по аналогии с англоязычной будет употребляться формулировка „оптическая накачка-зондирование“) в геометрии на отражение использовалась для измерения сверхбыстрой динамики неравновесных носителей заряда в исследуемых образцах. Экспериментальная установка описана в [9]. Экспериментальные результаты были интерпретированы при помощи

4 Письма в ЖТФ, 2017, том 43, вып. 22 


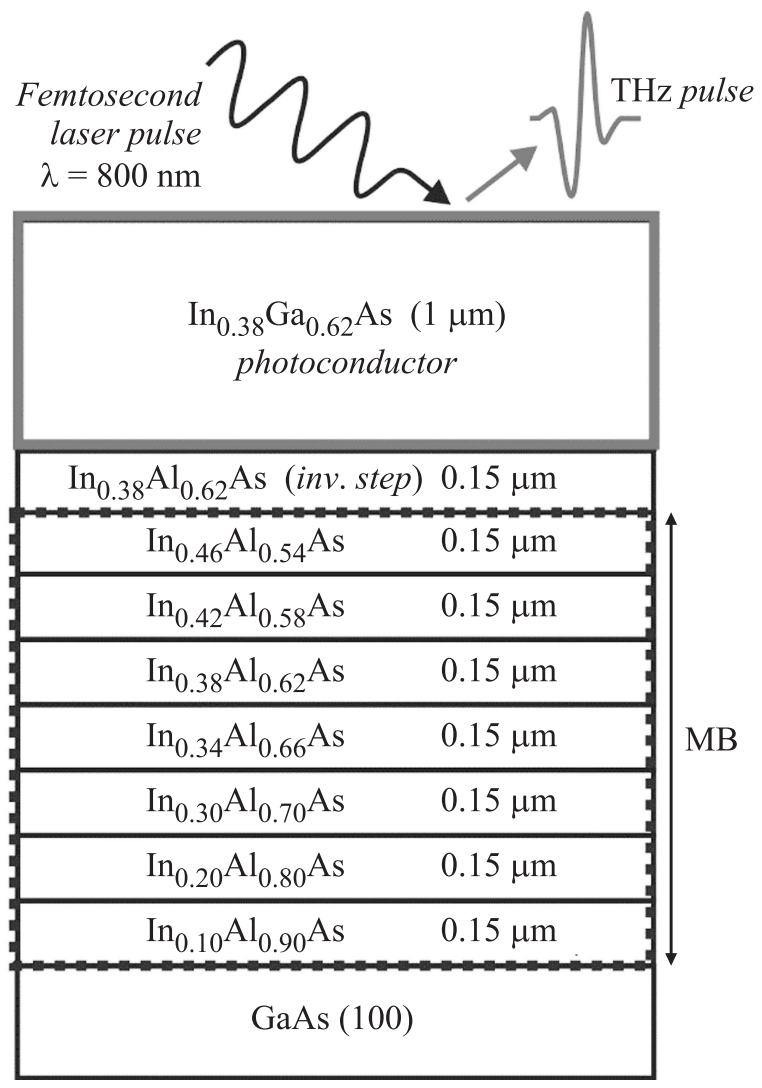

Рис. 1. Схема и толщины слоев образца $B$.

двухэкспоненциальной модели [10]:

$$
\begin{aligned}
\frac{\Delta R}{R}\left(t_{d}\right)= & \frac{A}{2} \exp \left(\frac{w^{2}}{4 t_{1}^{2}}-\frac{t_{d}}{t_{1}}\right)\left[\operatorname{erf}\left(\frac{t_{d}}{w}-\frac{w}{2 t_{1}}\right)+1\right] \\
& +\frac{B}{2} \exp \left(\frac{w^{2}}{4 t_{2}^{2}}-\frac{t_{d}}{t_{2}}\right)\left[\operatorname{erf}\left(\frac{t_{d}}{w}-\frac{w}{2 t_{2}}\right)+1\right],
\end{aligned}
$$

где $\Delta R$ - изменение интенсивности отраженного импульса зондирования, вызванное импульсом накачки; $R-$ интенсивность отраженного 


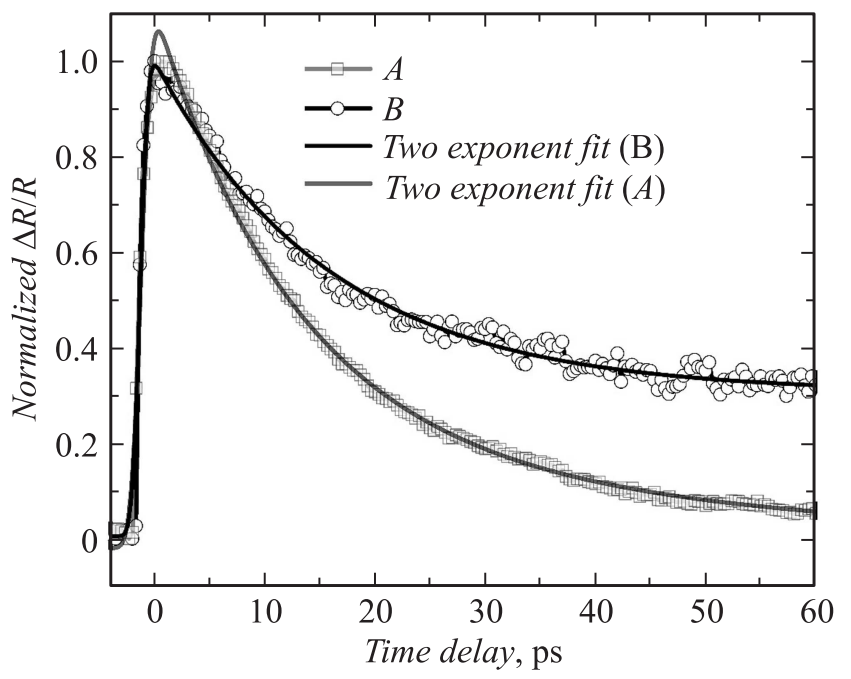

Рис. 2. Нормализованный сигнал $\Delta R / R$ для образцов $A$ и $B$.

импульса зондирования до воздействия импульса накачки; $t_{d}-$ время задержки между импульсами накачки и зондирования; $A, B$ - параметры подгонки; $w$ - время возбуждения; $t_{1}, t_{2}-$ временнб́е константы, которые характеризуют двухэкспоненциальную релаксационную зависимость. Экспериментальные зависимости $\Delta R / R\left(t_{d}\right)$ для обоих типов образцов представлены на рис. 2. Возбуждение неравновесных носителей заряда характеризуется резким ростом $\Delta R / R$ на временах $t_{d}<0$. Релаксационная часть характеризуется двумя частями: быстрым спадом $\Delta R / R$ на временах $0<t_{d}<20$ s и медленным спадом на временах $20<t_{d}<60$ ps.

Методика терагерцевой временно́й спектроскопии (THz-TDS) использовалась для измерения амплитуды THz-импульса во временно́м масштабе. Оптический импульс накачки со средней плотностью мощности $60 \mathrm{~mW}$ после прохождения через линию задержки фокусировался на поверхности образца при помощи объектива с пятикратным увеличением. THz-импульс генерировался в фотопроводящем слое образцов и собирался при помощи первого параболического зеркала, после чего фокусировался на поверхности кристалла детектора из

4* Письма в ЖТФ, 2017, том 43, вып. 22 


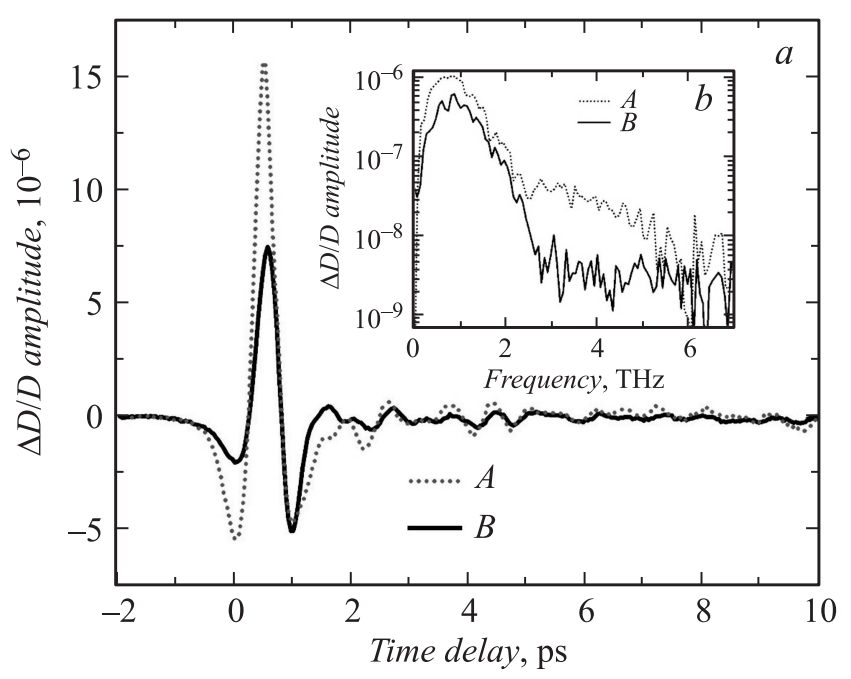

Рис. 3. Сравнение образцов $A$ и $B . a-$ сигнал $\Delta D / D$, индуцированный THz-импульсом; $b-$ БПФ сигнала $\Delta D / D$.

теллурида цинка $(\mathrm{ZnTe})$ при помощи второго параболического зеркала. Подробная сема установки представлена в [11]. Прошедший импульс зондирования через кристалл детектора регистрировался при помощи фотодиода и синхронного детектора. На пути зондирующего импульса были установлены поляризатор и анализатор, поляризации которых находились в скрещенном состоянии. Экспериментальные зависимости $\Delta D / D$ представлены на рис. $3, a$. Сигнал $\Delta D / D$ характеризуется спадом на временах $-1<t_{d}<0 \mathrm{ps}$, после которого следуют резкое увеличение сигнала и последующие осцилляции на временах $o<t_{d}<10 \mathrm{ps}$. Быстpoе преобразование Фурье (БПФ) сигнала $\Delta D / D$, индуцированного THz-импульсом, для образцов $A$ и $B$ представлено на рис. $3, b$. БПФ на рис. $3, b$ демонстрирует резкое увеличение амплитуды сигнала на частотах от 0 до $1 \mathrm{THz}$. В диапазоне от 1 до $6 \mathrm{THz}$ либо амплитуда спадает быстро (образец $B$ ), либо наблюдается слабый спад амплитуды (образце $A$ ).

Экспериментальные зависимости динамики неравновесных носителей заряда продемонстрировали расхождение для образцов $A$ и $B$. 
Константы времени жизни $t_{1}$ и $t_{2}$

\begin{tabular}{c|c|c}
\hline Образец & $t_{1}, \mathrm{ps}$ & $t_{2}, \mathrm{ps}$ \\
\hline$A$ & 12.7 & 52.5 \\
$B$ & 14 & $\gg 100$
\end{tabular}

Оба образца показали медленную релаксацию (медленный спад $\Delta R / R$ ) неравновесных носителей заряда, которая обусловлена рекомбинацией последних. При этом для образца $A$ спад $\Delta R / R$ происходил быстрее, чем для образца $B$. В результате аппроксимации были получены характерные времена жизни неравновесных носителей заряда, представленные в таблице. Видно, что образец $A$ обеспечивает меньшие времена жизни неравновесных носителей $t_{1}$ и $t_{2}$, чем образец $B$. Такое поведение $\Delta R / R$, возможно, обусловлено эпитаксиальными напряжениями в образце $A$ благодаря формированию дефектных или рекомбинационных центров в запрещенной зоне, которые позволяют сократить время жизни неравновесных носителей заряда [12].

Зависимости генерируемого образцами ТHz-импульса от времени показали почти двукратное увеличение его амплитуды для образца $A$. Снижение амплитуды генерируемого THz-импульса от образца $B$ может быть связано с переотражением THz-волн от слоев InAlAs в МБ.

БПФ сигнала $\Delta D / D$ (рис. $3, b$ ) показывает незначительные различия в спектре THz-излучения на частотах от 0 до $2 \mathrm{THz}$ для двух образцов. Видно, что для образца $A$ спектр шире, чем для образца $B$. На частотах от 2 до $6 \mathrm{THz}$ заметны значительные изменения в спектре. Частотный спектр THz-излучения для образца $B$ практически заканчивается на $3 \mathrm{THz}$ и выходит на уровень шума, в то время как частотный спектр образца $A$ заканчивается только на частоте $6 \mathrm{THz}$. Более широкий THz-спектр в образце $A$ обусловлен меньшим временем жизни фотовозбужденных носителей заряда, чем в образце $B$ [13].

В заключение методами оптической накачки-зондирования и TDS были исследованы образцы с фотопроводящим слоем $\operatorname{In}_{0.3} 8 \mathrm{Ga}_{0.62} \mathrm{As}$ без МБ и с переходным МБ ( $A$ и $B$ соответственно). Для интерпретации динамики неравновесных носителей использовалась двухэкспоненциальная аппроксимация, которая продемонстрировала снижение времени жизни неравновесных носителей заряда $t_{1}$ на 1.3 ps и $t_{2}$ более чем

Письма в ЖТФ, 2017, том 43, вып. 22 
в 2 раза для образца $A$. Методика TDS продемонстрировала увеличение $\Delta D / D$ сигнала, индуцированного THz-импульсом, почти в 2 раза для образца $A$ с эпитаксиальными напряжениями в фотопроводящем слое InGaAs. БПФ сигнала $\Delta D / D$ показало уширение THz-спектра и возникновение новых частот для образца $A$. В заключение следует отметить, что введение механических напряжений в эпитаксиальные слои является способом модификации свойств материалов на базе $\mathrm{In}_{y} \mathrm{Ga}_{1-y} \mathrm{As}$ и фотопроводящих антенн на их основе.

Работа выполнена при финансовой поддержке Министерства образования и науки РФ (государственное задание № 3.7331.2017 9.10) и грантов РФФИ 16-07-00187А и 16-29-14029 офи_м. Экспериментальная часть работы по эпитаксиальному росту образцов выполнена А.Э. Ячменевым и Д.С. Пономаревым при финансовой поддержке гранта РНФ 14-29-00277.

\section{Список литературы}

[1] Jepsen P.U. et al. // Laser Photon. Rev. 2011. V. 5. P. 124.

[2] Falconer R.J. et al. // J. Infrared Millimeter Terahertz Waves. 2012. V. 33. P. 973.

[3] Federici J.F. et al. // Semicond. Sci. Technol. 2005. V. 20. P. S266.

[4] Berry C.W. // Nature Commun. 2013. V. 4. P. 1610.

[5] Globisch B. et al. // J. Appl. Phys. 2017. V. 121. P. 053102.

[6] Галиев Г.Б. и др. // Рос. нанотехнологии. 2015. Т. 10. № 7-8. С. 69.

[7] Galiev G.B. et al. // J. Cryst. Growth. 2014. V. 392. P. 11.

[8] Пономарев Д.С. и др. // ФТП. 2017. Т. 51. С. 535.

[9] Khusyainov D.I. et al. // J. Mod. Phys. B. 2017. V. 31. P. 1.

[10] Kimel A.V. et al. // Phys. Rev. B. 2001. V. 63. P. 235201.

[11] Галиев Г.Б. и др. // ФТП. 2017. Т. 51. Р. 529.

[12] Ortiz V. et al. // J. Appl. Phys. 2007. V. 102. P. 043515.

[13] Wells N.P. et al. // J. Appl. Phys. 2014. V. 116. P. 073506. 